\title{
LA PROPIEDAD DE TIERRAS EN LA MORERÍA DE CASTELLÓ DE LA PLANA: 1462-1527
}

Por

CARMEN DÍAZ DE RÁBAGO

Universidad Jaume I, Castelló de la Plana

\section{1.- Introducción}

La situación económica de los musulmanes valencianos sufrió bastantes cambios desde la conquista de inicios del siglo XIII hasta el siglo XIV. También en su aspecto cuantitativo sufrieron un progresivo descenso demográfico (1) y a mediados o más bien finales del siglo XIV dejaron de ser globalmente mayoría (2).

Las aljamas urbanas de la València bajomedieval son una muestra de la situación minoritaria en que quedaron algunos musulmanes (3). Desde la conquista y en adelante, a lo largo de los siglos XIII y XIV, las principales ciudades y villas del reino (4) se fueron vaciando de musulmanes. En algunos lugares, como Xàtiva o València, perduraron grupos minoritarios de mudéjares formando morerías o barrios específicos de moros.

En otros lugares, como fue el caso de la villa medieval de Castelló de la Plana, la antigua población mayoritaria musulmana perdió su fuerza frente a la presión del poder cristiano y se dispersó por completo en la primera mitad del siglo XIV, no quedando siquiera morería.

(1) Otras zonas, como la cuenca del Millars o la serra d'Espadà, conservaron o incluso aumentaron su población musulmana al trasladarse allí musulmanes de otras zonas atacadas por el poder cristiano.

(2) Meyerson, M.D.: The Muslims of Valencia: in the age of Fernando and Isabel. Between coexistence and crusade, University of California Press, Berkeley, Los Angeles, Oxford, USA, 1991.

(3) La mayoría de musulmanes residió en lugares rurales, sobre todo de señorío.

(4) Siendo más acusado en las zonas del norte y del litoral. 
Éste no fue el único caso de pérdida poblacional, por lo que ya desde el siglo XIV y durante el siglo XV, y en plena crisis demográfica, el monarca cambió su postura de relegar a los mudéjares y, en adelante, comenzamos a ver documentados sucesivos intentos de crear morerías en núcleos urbanos de realengo (5).

Con esta misma actitud concedió el rey Martín el Humano en 1402 un privilegio a la villa de Castelló para poder crear en ella una nueva aljama de musulmanes, que se sustentará y perdurará hasta la expulsión de 1609, manteniendo un nivel de propiedad suficiente para ello.

\section{2.- Fuentes para el estudio de la propiedad de la tierra}

El estudio global que hemos realizado sobre la morería de Castelló ha partido de unas fuentes documentales que son privilegiadas, ya que no se dispone de ellas para el estudio de otras aljamas musulmanas del reino (excepto el caso de Alzira). Se trata de los «Llibres de vàlues de la Peyta», que contienen inmuebles. Con esto, se ha podido hacer una reestructuración de la aljama castellonense durante la baja edad media, cosa que sólo se había hecho hasta ahora con la aljama de Alzira (6). Así, hemos catalogado diversas variables a partir de dicha fuente (7): población global de la morería, nivel de riqueza relativo, propiedad de tierras, propiedad de inmuebles urbanos e incluso composición familiar del grupo.

Nos centraremos en el presente artículo en el aspecto de la propiedad de la tierra dentro del término municipal de Castelló, pues los campesinos podían tener parcelas en diversos términos municipales, sin dejar de mencionar desde el principio cuál es el tamaño del grupo y su evolución para comprender mejor el sentido de las cifras aportadas.

\section{3.- Población de la morería}

Al igual que en todas las aljamas urbanas valencianas, los musulmanes de Castelló eran una minoría.

A continuación mostramos en dos gráficos el número global de pobladores mudéjares así como su porcentaje dentro de la villa:

Si el privilegio de crear una aljama lo dio el rey en 1402, hasta 1459 no llega a la villa una cantidad considerable de pobladores, pero a partir de este año hay una estabilización de población musulmana, que como hemos podido comprobar continúa durante el siglo XV y mengua en el siglo XVI, debido a una progresiva coerción de la cultura islámica, que culmina con la conversión forzo-

(5) Por ejemplo en Monfort y Oriola, cit. por C. Barceló: Minorias Islámicas en el País Valenciano: historia y dialecto, Univ. de Valencia/Instituto Hispano-Árabe de Cultura, València, 1984, pp. 54 y 57.

(6) Peris Albentosa, V.: La estructura de la propiedad en la morería de Alcira (1508-1579), tesis de licenciatura, Univ. de Valencia, junio, 1977, inédita.

(7) Completando con diversas fuentes como los «Llibres de Compres i Vendes" o los «Llibres de Consell», ambos del Archivo Municipal de Castelló. 
sa de los musulmanes valencianos en 1525 y la supresión oficial de las autoridades islámicas.

\section{Propietarios de la aljama musulmana}
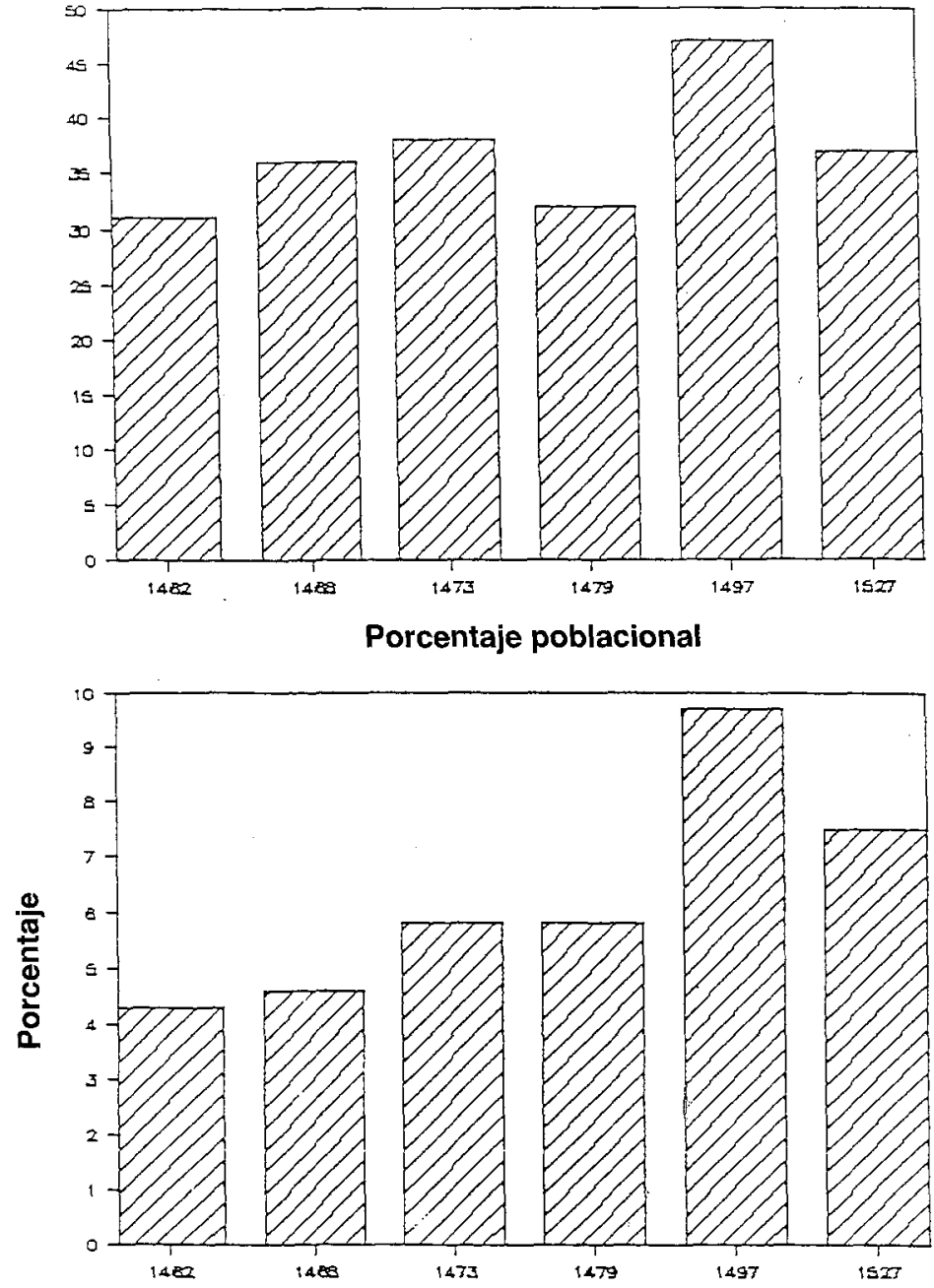

Durante el siglo XV, los hogares de la morería oscilarán entre 30 y 47 fuegos, ocupando a su vez entre un 4 y un $9{ }^{\prime} 5 \%$ del total de la población de la villa.

\section{4.- Los bienes raíces}

A partir de la fuente fundamental que hemos analizado, la peita, no es posible conocer el nivel de riqueza por hogar al cien por cien, ya que no esta- 
ban registrados fiscalmente los animales de tiro ni los talleres o herramientas artesanales. En cambio, sí que podemos conocer la tierra poseída, las casas y algunos animales (ganado menor y colmenas de abejas).

\section{La propiedad de tierras}

Más del $80 \%$ de los cabezas de familia de la aljama poseían tierras. A pesar de ser la villa de Castelló un centro de intercambio comarcal, su carácter agrícola era en cualquier caso predominante. La fertilidad de las tierras de la Plana, con una red de regadíos (8) organizada, permitió una diversidad de cultivos que atrajo a los pobladores de zonas de secano y de montaña del interior.

La diversidad de cultivos y sus valores en el mercado obedecian a distintos factores: calidad, productividad y lindes del terreno, además del grado de proximidad de las parcelas al núcleo urbano, lo cual aumentaba su valor.

Tanto cristianos como musulmanes cultivaban las mismas especies y tenían tierras por todo el término municipal. Así, la principal diferencia entre unos y otros no era tanto cualitativa como cuantitativa, ya que el labrador cristiano, en general, tenía un mayor nivel de propiedad que los musulmanes.

La tipología de las tierras era variada, y señalaremos a continuación los tipos más frecuentes:

- Terra o Terra campa.- Es la tierra de sembradura, con cultivos no arbóreos, sobre todo cereal (9), hortalizas y legumbres. Es el tipo más frecuente, no bajando nunca del $30 \%$ del total de cultivos.

- Huertos.- Son parcelas dedicadas sobre todo a frutales y también hortalizas (10). Pasarán de constituir en 1462 el 5'5\% de la propiedad global a un $14 ' 9 \%$ en 1527.

- Marjal.- Es la tierra de menor valor fiscal, por el carácter pantanoso y trabajoso de la misma. Disminuye progresivamente desde 1462 a 1527, de un $17^{\prime} 7 \%$ del total de la propiedad a un $0^{\prime} 5 \%$. Esto hace pensar en una reconversión de este tipo de tierras o bien en un abandono de las mismas, aunque nos inclinamos por pensar que hubo una desecación y un posterior aumento de su valor fiscal.

- Arbóreos.- Aquí se incluye el algarrobo, que era importante cuantitativamente en la villa de Castelló. Mientras en la morería de Alzira ocupaba el $2 \%$ de la propiedad (11), en Castelló supone entre un $10 \%$ y un $25 \%$ de la propiedad de musulmanes. Según B. Bennassar, el algarrobo en Castelló tuvo un carácter mercantil (12), y debemos relacionarlo en el caso que nos ocupa con

\footnotetext{
(8) Heredada parcialmente de los musulmanes autóctonos del siglo XIII.

(9) «Forment», «blat», Archivo Municipal de Castelló, Corte del Justicia, 1466, fols. 22 v, 29 r, 47 v.

(10) Furió, A.: Camperols del País Valencià, Institució Alfons el Magnànim, València, 1982, p. 81.

(11) Peris Albentosa, V.: 1977, op. cit., p. 142.

(12) Bennassar, B. (dir): Historia de los españoles, t. I, ed. Crítica, Barcelona, 1989, p. 501.
} 
algunas familias de traginers musulmanes de la morería, como los Bocayo (13).

La viña también era cultivada por los musulmanes, aunque supone sólo entre un $2 ' 8 \%$ y un $4 ' 2 \%$ del total de la propiedad. En cualquier caso, y a pesar de su escasez, es importante señalar que el $70 \%$ de los miembros de la morería poseían alguna parcela de este tipo.

También se poseían olivos, parcelas de tipo mixto (arbóreos/terra campa, arbóreos/alquería o corral, terra/alquería o corral, etc...), higueras, eras, eriales (14), y moreras en menor medida. En el siguiente gráfico mostramos la proporción de cada cultivo en la propiedad global de los musulmanes de Castelló entre 1462 y 1527 (15):

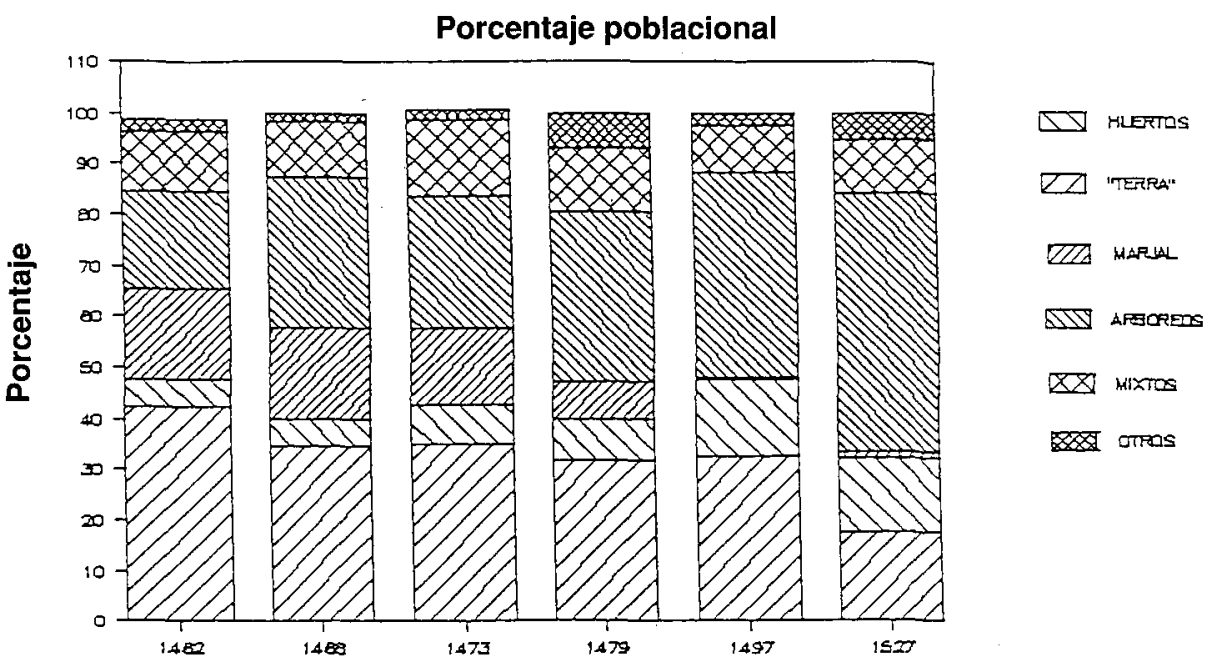

La parcelación

En el siglo XV la distribución parcelaria ha sufrido una evolución desde el siglo XIII, pues hay una tendencia a su reducción. A su vez, hay una dispersión parcelaria. El modelo general consiste en una distribución de la propiedad en pequeñas parcelas que a su vez se dedican a distintos cultivos. Se trata de cubrir las distintas necesidades familiares y de obtener pequeños excedentes de algunos cultivos, como el algarrobo, el olivo o los productos de huerta en los casos que nos ocupan.

El carácter minifundista es en cualquier caso una característica de la propiedad general en las llanuras litorales valencianas, incluso tratándose de propietarios ricos.

(13) Archivo Municipal de Castelló (en adelante AMC), Cort del Justícia, 1488, junio, 16, s/n.

(14) Domingo, C.: «La agricultura de Castellón de la Plana: 1468», Saitabi, t. 27-28, València, 1977-78, p. 232.

(15) Con valores en hanegadas: 1 hanegada $=833 \mathrm{~m}^{2}$. 
En la siguiente tabla mostramos la hanegadas y las parcelas por propietario musulmán resultantes de cada año estudiado:

Tabla de hanegadas y parcelas por propietario

\begin{tabular}{|c|c|c|c|c|c|c|}
\hline AÑO & 1462 & 1468 & 1473 & 1479 & 1497 & 1527 \\
\hline Hanegadas ................ & $36^{\prime} 6$ & $29 \cdot 8$ & $39^{\prime} 80$ & $48^{\prime} 9$ & $32 ' 4$ & $37 ' 7$ \\
\hline Hectáreas... & $3^{\prime} 05$ & $2^{\prime} 4$ & $3^{\prime} 30$ & $4^{\prime} 0$ & 27 & $3 ' 1$ \\
\hline 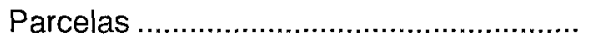 & 4'5 & $5 \cdot 1$ & $5^{\prime} 00$ & $6{ }^{\prime} 0$ & $4^{\prime} 4$ & $5^{\prime} 8$ \\
\hline Parcela media (en hanegadas) ................. & $8^{\prime} 1$ & $5^{\prime} 8$ & $7^{\prime} 96$ & $8^{\prime} 1$ & $7 ' 3$ & $6^{\prime} 5$ \\
\hline
\end{tabular}

Como vemos, son parcelas de menos de 10 hanegadas, y esto viene a confirmar la tesis de $\mathrm{C}$. Domingo según la cual el $60 \%$ de las parcelas en tierras valencianas tenían menos de una hectárea (12 hanegadas).

La escasez de trabajos sobre la propiedad mudéjar no permite de momento hacer muchas comparaciones, pero al menos tenemos como referente el estudio de la propiedad en la morería de Alzira durante el siglo XVI (16), en la que hay una media de 15'2 a 28'6 hanegadas por propietario (17), cuando en Castelló el nivel es prácticamente el doble, pues encontramos, entre $29 ' 8$ y 48'9 hanegadas por propietario musulmán.

Modo de tenencia de la tierra

Los musulmanes de la aljama poseían tierras libres o alodiales (francas) y tierras censadas.

- Propiedad libre.- Son las predominantes, y hay que señalar que es algo corriente en el siglo XV valenciano. Su mayor porcentaje sobre tierras censadas puede en cualquier caso obedecer a las condiciones favorables que se establecían al crearse nuevas aljamas.

- Propiedad censada.- Constituye un porcentaje que no llega nunca al $45 \%$ en los años estudiados. Hay que hacer una distinción entre censos enfitéuticos y censales, los cuales no se indican en los registros de la peita. Por ello, hemos consultado los "Llibres de Compres i Vendes" (18), y en ellos se indica de vez en cuando los contratos de enfiteusis, que parecen ser los mayoritarios en cuanto a tierras censadas se refiere. He aquí algunos ejemplos:

- 1475: Mahomat Royo tenía 1 quartó en peyta a censo enfitéutico (19).

- 1460: Jucef Sanpol posee tierra establida per mossén Palau (20).

- 1460: La villa hace establiment a Çalé Arrocet de una casa valorada en 100 sueldos (21).

(16) Peris Albentosa, V:: op., cit., 1977.

(17) Peris Albentosa, V.: lidem, p. 331.

(18) Años 1455, 1460, 1469, del Archivo Municipal de Castelló.

(19) AMC, Compres i Vendes, $1460, \mathrm{~s} / \mathrm{n}$.

(20) AMC, Compres i Vendes, 1460, s/n

(21) AMG, Compres i Vendes, $1460, \mathrm{~s} / \mathrm{n}$ 


\section{Propiedad de inmuebles urbanos}

La posesión de casas propias y el mantenimiento de las mismas en un barrio propio creemos que fue un factor importante para la perduración de la morería. El hogar familiar, el alberch, es el edificio predominante, ya que supone el lugar de residencia de cada familia, y es a su vez el tipo de edificio más valorado fiscalmente entre las propiedades de musulmanes. Otros edificios, como casas o corrales, tienen un menor valor fiscal.

Entre el alberch y la casa surge la dificultad de definirlos con nitidez. Durante el siglo XV los hogares familiares son llamados siempre alberchs, y observamos que a finales del período estudiado, en 1527, el alberch ya no aparece, y los hogares de residencia familiar son llamados siempre «casas". En 1479 aparece por primera vez mencionada una botigueta o pequeña tienda, que más que una novedad su mención parece obedecer a una mayor precisión del escribano, pues en adelante la mención de botigues aumentará.

El porcentaje de propietarios de edificios en la aljama no es del cien por cien, sino que oscila entre el 65 ' $9 \%$ y el $93 \%$. Aunque la mayoría de propietarios poseen casas, hay un porcentaje que no tienen casa propia. Las razones pueden ser diversas: A) pueden ser viudas, que pasan a vivir con sus hijos pero aún poseen tierras propias y por ello aparecen anotadas en la peita; B) pueden ser hijos que tienen tierra propia pero aún residen con sus padres, y C) pueden ser vecinos eventuales de la aljama, que por su nivel de riqueza reducido parecen ser mano de obra asalariada.

El valor fiscal (en sueldos) de los edificios de la aljama aumenta progresivamente, lo cual es un síntoma del asentamiento del grupo en Castelló. En el cuadro siguiente mostramos la evolución:

Valor de los edificios

\begin{tabular}{lccccc}
\hline 1462 & 1468 & 1473 & 1479 & 1497 & 1527 \\
\hline $5.200^{*}$ & 5.950 & 7.500 & 8.125 & 8.700 & 10.400 \\
\hline${ }^{*}$ en sueldos & & & & &
\end{tabular}

Todo lo referido anteriormente nos muestra las características de la propiedad en una aljama urbana de la València bajomedieval.

El siglo XV supone para el grupo de musulmanes de Castellón un período de avance y de afianzamiento económico, aunque a pequeña escala, pues los mudéjares tuvieron límites para su participación tanto en el comercio a gran escala como en la política y administración de los consejos municipales o en los oficios organizados. Asi, conformando su propia aljama o comunidad, y con una administración interna separada de la cristiana, la comunidad musulmana de Castelló tuvo un nivel de riqueza medio-bajo pero suficiente para afianzarse poco a poco. Las actividades artesanales, extra-agrícolas o de comercio al por menor no han sido susceptibles de ser analizadas por su exclusión de los registros fiscales estudiados. Su existencia, esporádicamente mencionada en otro tipo de fuentes (llibres de consells, Cort del justícia), nos debe llevar a un nivel de riqueza algo más elevado del que presentan los registros fiscales. 
Así, la idea de un declive progresivo de los musulmanes valencianos desde el siglo XIII hasta su expulsión en el XVII se ve quebrada ante este caso, que no es el único, de mudéjares que se ven favorecidos por el rey y la misma población cristiana para mejorar la economía de ciertos lugares del reino. El concepto de tolerancia en la época a que nos referimos, era un producto de la vida material, no un ideal político o religioso (22). Será en las primeras décadas del siglo XVI (guerra de las Germanías y conversión forzosa en 1525) cuando ese ideal político-religioso comenzará a hacerse sentir cada vez más.

(22) Meyerson: op. cit., 1991, p. 114. 